\title{
Dilatometry of Refractory Metals and Alloys Using Multi- Wavelength Laser Shadowgraphy of Filament Samples
}

\author{
H. S. Ayoub ${ }^{1}$, Ashraf. El-Sherif ${ }^{2}$, H. H. Hassan ${ }^{2}$, S. A. Khairy ${ }^{3}$ \\ ${ }_{1,3,4}$ Department of Physics, Faculty of Science, Cairo University, Egypt \\ ${ }^{2}$ Laser Photonics Research Center, Engineering Physics Department, \\ Military Technical College, Cairo, Egypt
}

\begin{abstract}
:
In this work, we discuss a new technique for measuring the linear thermal expansion of refractory metals and alloys over their entire temperature range from room to near melting. The technique is based on generating multi-wavelength laser shadowgraphs for filament wire samples under gradual heating, and measuring the dimensional changes from its shadowgraphs using digital camera. The samples are clamped from both ends and joule heated by direct current under vacuum. The measurements are non-contact and accurate, enabling low cost dilatometric measurements that help in future synthesis and test of new grade of refractory materials, used as plasma facing material in nuclear fusion reactor, or special super alloys for high temperature applications were thermal structural stability are required.
\end{abstract}

\section{Keywords:}

Elevated temperatures, Filament dilatometry, Linear expansion, Low cost multiwavelength laser shadowgraphy, Refractory materials.

\section{Background}

Refractory metals (Niobium, Molybdenum, Tantalum, Tungsten, and Rhenium) can be defined as those metals exhibiting melting points greater than $2273 \mathrm{~K}$. Their alloys are vital materials to virtually every major industry and to many branches of applied sciences including aerospace, automotive, nuclear technology, lighting, metal processing, mining, electronics and prosthetics. They share some distinguished properties, including, high melting point, high hardness at room temperature, they have a relatively high density and they are stable against creep deformation to very high temperatures. Their thermal expansion is one of important thermo physical characteristics [1]. The development of several applications in modern science and technology place a heavy demand on the accurate knowledge of their thermal expansivity, in order to prevent the generation of harmful internal stress when a structural part is heated and kept at constant length, and therefore achieving optimum designs to guarantee safety. For example, nano-science, is producing new refractory materials with unusual microstructure and mechanical behavior that requires efficient dilatometric investigation [2]. The thermal expansion of refractory materials is measured by special 
Military Technical College

Kobry Elkobbah, Cairo, Egypt

April 3-5,2018 9th International Conference

on Mathematics and

Engineering Physics (ICMEP-9)

dilatometers [3, 4], capabale of performing elevated temperature extensometry and thermometry simultaneously (as shown in figure 1).

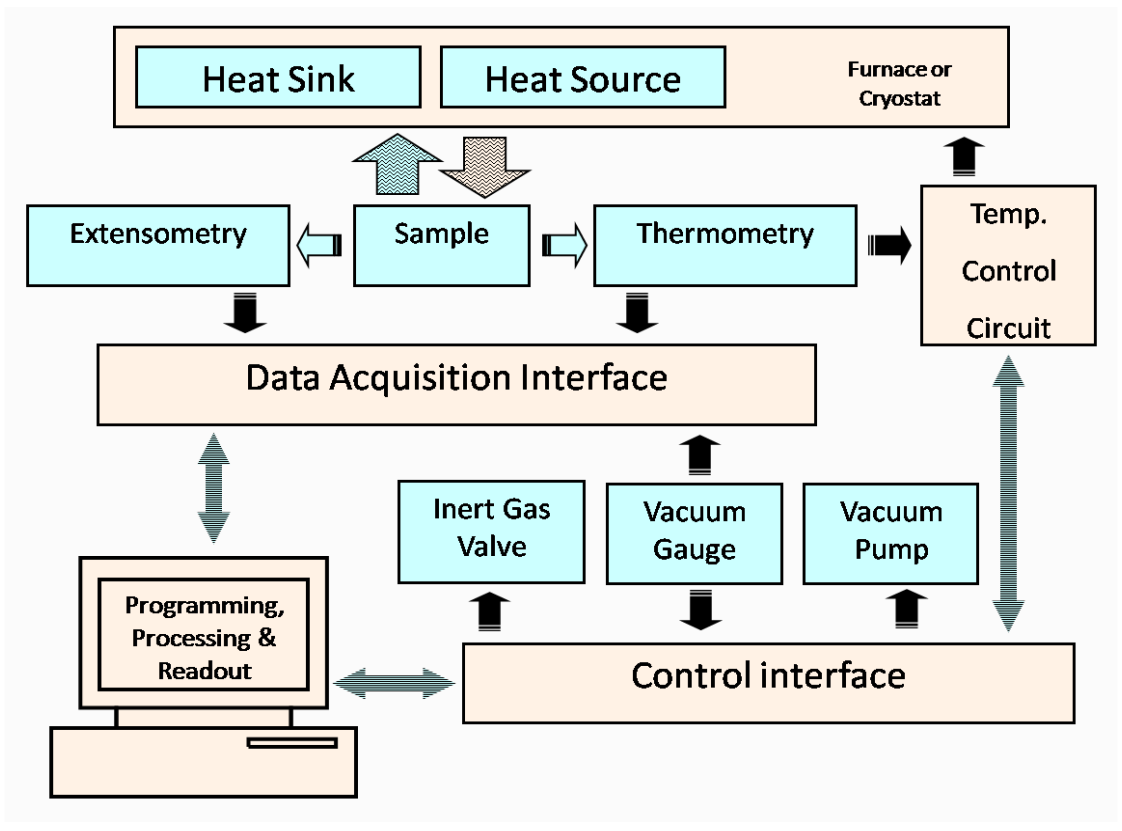

Figure 1. Block diagram of a modern dilatometer

The basic components of a modern dilatometer include six part; the sample, the sample cage or carrier, the heat source or sink, the thermometry, the extensometry, and the environment (These components are discussed briefly in table 1). According to the manufacturer brochures [5] modern dilatometers often have a common functional diagram where computer controls the whole measuring processes and data accusation, allowing measurements that include thermal expansion, CTE, annealing studies, determination of phase transitions and the glass transition, softening points, kinetics studies, construction of phase diagrams and sintering studies, including the determination of sintering temperature, sintering step and ratecontrolled sintering Investigation of processing parameters as reflected by dimensional changes of the material can be studied in great detail through exact duplication of thermal cycles and rates used in the actual process.

Table 1 basic components of a modern dilatometer

\begin{tabular}{|l|ll|}
\hline $\begin{array}{l}\text { Structure of the } \\
\text { dilatometer }\end{array}$ & & \multicolumn{1}{c|}{ Properties } \\
\hline The Sample & $\bullet$ & powder, sheets, rods (most used), wires \\
\hline $\begin{array}{l}\text { The Sample Cage } \\
\text { or Carrier }\end{array}$ & $\bullet$ & $\begin{array}{l}\text { free end, single fixed end to fixed-fixed end } \\
\text { vertical or horizontal type }\end{array}$ \\
\hline
\end{tabular}


Military Technical College

Kobry Elkobbah,

Cairo, Egypt

April 3-5,2018 9th International Conference

on Mathematics and

Engineering Physics (ICMEP-9)

\begin{tabular}{|c|c|}
\hline $\begin{array}{l}\text { The Heat Source } \\
\text { or Sink }\end{array}$ & $\begin{array}{l}\text { - electric heater coil, gas flame, microwave, ultrasound, electron beam, infrared or laser beam. and } \\
\text { Joule heating by electric current or electromagnetic induction. } \\
\text { - } \quad \text { cooling, by water, inert gas flow, liquid nitrogen or helium for cryogenic temperatures dilatometry. }\end{array}$ \\
\hline The Thermometry & $\begin{array}{l}\text { - contacting techniques: thermocouples, thermistors, electric resistivity of the sample, ultrasound } \\
\text { propagation and metrology thermometers. } \\
\text { - Non-contacting techniques: pyrometers, bolometer, reference spectrometry and thermal cameras } \\
\text { detectors. }\end{array}$ \\
\hline The Extensometry & $\begin{array}{l}\text { - } \quad \text { Surface techniques include metrological, mechanical, electric, optical, and laser methods. } \\
\text { - } \quad \text { subsurface techniques include acoustic, X-ray, } \Gamma \text {-ray, electron beam and neutron beam methods. }\end{array}$ \\
\hline The Environment & $\begin{array}{ll}- & \text { Vacuum } \\
\text { - } & \text { Inert gas } \\
\end{array}$ \\
\hline
\end{tabular}

Dilatometry techniques are numerous, the selection of the suitable technique depends upon the nature of the sample, the temperature range of the measurement and the resolution of the measurement. To evaluate different dilatometry techniques, Table (2) summarizes the resolution of each one [6].

Table 2. Resolution of Different Dilatometry Techniques.

\begin{tabular}{|l|l|l|l|}
\hline \multicolumn{1}{|c|}{ The Technique } & \multicolumn{1}{|c|}{$\begin{array}{c}\text { Resolution } \\
(\mathbf{m})\end{array}$} & \multicolumn{1}{|c|}{ The Technique } & \multicolumn{1}{c|}{$\begin{array}{c}\text { Resolution } \\
(\mathbf{m})\end{array}$} \\
\hline Push Rod & $10^{-5}$ & Modulation Calorimetry & $10^{-7}$ \\
\hline Strain Gauge & $10^{-7}$ & Ultrasound & $10^{-5}$ \\
\hline LVDT & $10^{-8}$ & Microwave & $10^{-12}$ \\
\hline Capacitive Technique & $10^{-10}$ & Electron Diffraction & $10^{-14}$ \\
\hline Optical Comparators & $10^{-6}$ & Neutron Diffraction & $10^{-14}$ \\
\hline Laser (Non Interferometric) & $10^{-6}-10^{-8}$ & X- Ray Diffraction & $10^{-14}$ \\
\hline Laser Interferometers & $10^{-7}-10^{-9}$ & $\Gamma$ - Ray Attenuation & $10^{-14}$ \\
\hline
\end{tabular}

Obviously, the most sensitive techniques are those based on capacitance and high energy particle diffraction, unfortunately, capacitance technique is used for low temperature measurements, and high energy particle techniques may cause transmutation of the sample in some cases. However, non-interferometric laser techniques (including shadowgraphy) are suitable for high temperatures measurements with reasonable resolution. Other techniques are neither suitable for this temperature range or of enough sensitivity. There is so many problems associated with elevated temperature dilatometry, which can affect the accuracy of the measurement, these problems are summarized in table 3.

Table 3. Problems associated with elevated temperature dilatometry

\begin{tabular}{|c|c|}
\hline Problem type & Details \\
\hline $\begin{array}{l}\text { Problems Related } \\
\text { to Sample }\end{array}$ & $\begin{array}{l}\text { - Thermal expansion at high temperatures is associated with physical instability of the sample } \\
\text { specially when using push rod techniques. } \\
\text { - Some dilatometers require special treatment of the samples test material (i.e. optical flat, } \\
\text { polished surface, special roughness, knife edge marks ...). } \\
\text { - Some dilatometers require samples of standard dimensions that may need the preparation of } \\
\text { massive quantity of test material. }\end{array}$ \\
\hline $\begin{array}{l}\text { Problems Related } \\
\text { to Dilatometer }\end{array}$ & $\begin{array}{l}\text { - Most of the measurements are made under vacuum or in presence of inert gas atmosphere to } \\
\text { avoid oxidization of the incandescent sample. } \\
\text { Metallurgical applications often involve sophisticated temperature controls capable of applying } \\
\text { precise temperature-time profiles for heating and quenching the sample. } \\
\text { - Dilatometry requests precise contact thermometry based on thermocouples that probe the surface } \\
\text { of the sample under test, and may not be able to sense the real temperature of the sample's core. } \\
\text { Also some dilatometers use special non-contact pyrometers that measure the apparent radiant } \\
\text { temperature of the sample. }\end{array}$ \\
\hline
\end{tabular}


Military Technical College

Kobry Elkobbah,

Cairo, Egypt

April 3-5,2018 9th International Conference

on Mathematics and

Engineering Physics (ICMEP-9)

\begin{tabular}{|l|ll|}
\hline & $\bullet \begin{array}{l}\text { Powerful heaters and special furnace modified for measurements at elevated temperatures (up to } \\
\left.2700^{\circ} \mathrm{C}\right) .\end{array}$ \\
\hline
\end{tabular}

We decided to use shadowgraphy to prevent most of the previously cited problems, in order to ease the measurements, reduce the mass of the sample, decrease the time of heating.

\section{Theory}

To achieve our goal, it was a must to increase the length of the sample as possible to obtain a noticeable expansion during testing and therefore being able to exclude any sophisticated technique such as interferometry or high resolution photography from the experiment that uses only a modest digital camera to detect such expansion. On the other hand it is very hard to sustain a long sample with relatively small diameter straight at incandescence temperatures. To overcome this technical problem it is necessary to change the symmetry of the sample from short cylinder bar to uniformly coiled wire (assuming that the sample material is ductile) and change the fixation method from single fixed end to fixedfixed end, and this could lead to the reduction of containing volume for the sample (as seen in figure 2)

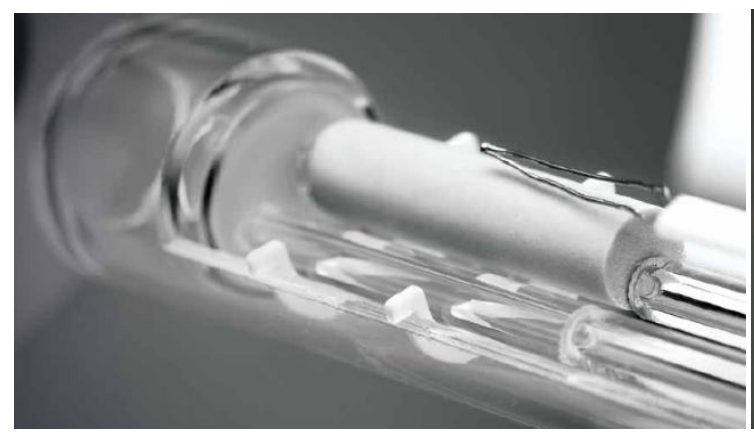

(a)

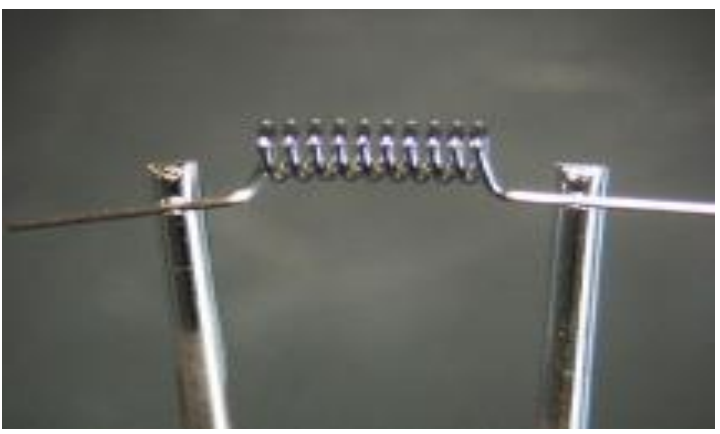

(b)

Figure 2. Comparison between traditional and proposed sample layout; (a) traditional rod sample in fixed-end pushrod fused silica cage with thermocouple, (b) proposed filament wire sample in fixed-fixed end mount.

A comparison showing major differences between traditional and proposed method are featured in table 4, revealing the advantages of filament sample layout in the ease of the measurement, and the reduction of sample mass.

Table 4. basic features of traditional and proposed method

\begin{tabular}{|l|l|l|}
\hline \multicolumn{1}{|c|}{ Features } & \multicolumn{1}{c|}{ Traditional method } & \multicolumn{1}{c|}{ Proposed method } \\
\hline Sample Shape & Cylinder & Helical Coil \\
\hline Diameter & $1-12 \mathrm{~mm}$ & $0.001-0.4 \mathrm{~mm}$ \\
\hline Length & $7-25 \mathrm{~mm}$ & $7-50 \mathrm{~mm}$ \\
\hline Heat Source & Furness & Joule Heating \\
\hline Temperature sensor & Thermocouple & Sample resistivity \\
\hline
\end{tabular}


Military Technical College

Kobry Elkobbah, Cairo, Egypt

April 3-5,2018 9th International Conference

on Mathematics and

Engineering Physics (ICMEP-9)

\begin{tabular}{|l|l|l|}
\hline Temperature range & Up to $2400 \mathrm{~K}$ & Up to $3400 \mathrm{~K}$ \\
\hline Clampping method & Fixed end & fixed- fixed end \\
\hline
\end{tabular}

Theoretically, the expansion of the filament sample made of a wire of length $l$ can be measured as a function of wire diameter $d$ or as a function of filament diameter $D$. In our case its easer to measure $\Delta D$ rather than $\Delta D$, hence the linear expansion of the sample $\frac{\Delta l}{l}$ can be calculated as:

$$
\frac{\Delta l}{l} \approx \frac{\Delta D}{D}
$$

The temperature $T$ of the filament sample can be obtained from the change of its resistance $R$ by using the formalism of exponents [7] from the equation :

$$
\frac{T}{T_{o}}=\left(\frac{R}{R_{o}}\right)^{x}
$$

Where the value of $x$ depends of the resistivity of the material and the subscript o denotes the room temperature value.

\section{Experimental setup}

We decided to test our technique on a standard automotive lamp sample type P21 previously used in many works, to measure the linear expansion of non-sag tungsten. The reason behind this choice is the fact that the geometry of the lamp filament is exactly matching our theoretical needs. Therefore we designed a standard shadowgraphy setup (as shown in figure 3) to generate shadowgraphs for the filament lamp during it incandescence.

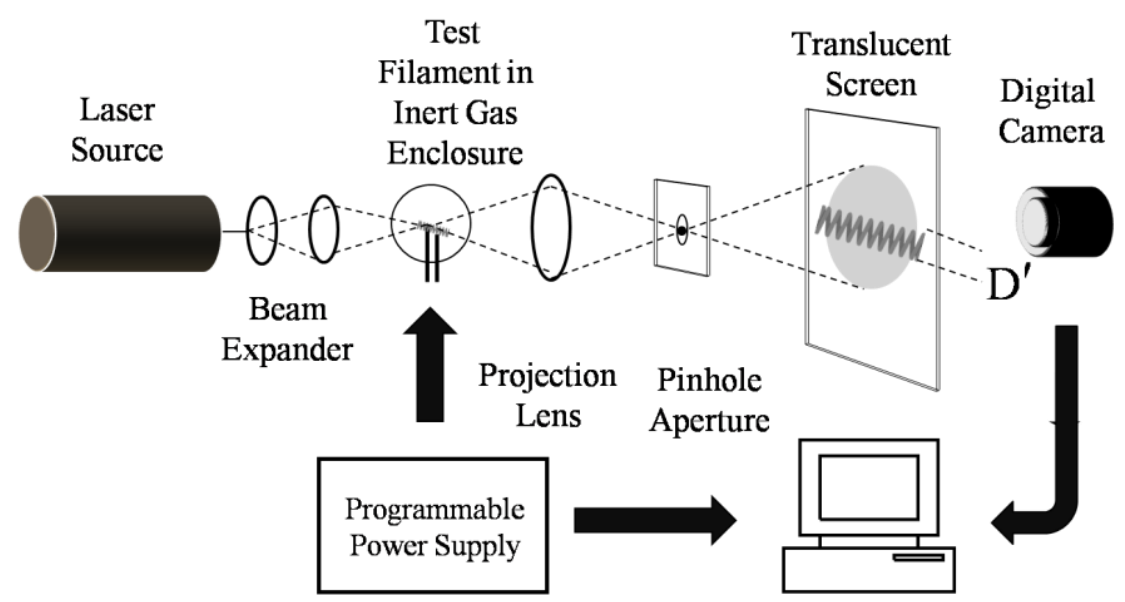

Figure 3. Block diagram of filament dilatometer 
Military Technical College

Kobry Elkobbah, Cairo, Egypt

April 3-5,2018 9th International Conference

on Mathematics and

Engineering Physics (ICMEP-9)

Assuming $\mathrm{x}=0.83$ [8], the temperature of incandescent tungsten coil (filament) is calculated from the equation:

$$
\frac{T}{T_{o}}=\left(\frac{R}{R_{o}}\right)^{0.83}
$$

In shadowgraphy setup [9], the object under test is placed near the focal plane of convex throw lens of focal length $f$, and then backlighted by laser beam so that, the shadowgraph of the object is project at throw distance $D_{\text {Shadow }}$ With magnification factor $M$ is given by the equation:

$$
M=\frac{D_{\text {Shadow }}-f}{f}=\frac{D_{o}^{\prime}}{D_{o}}
$$

If the object undergoes a small in-plane position shift due to vibration, then this shift will be magnified at the shadowgraph plan by a factor of $M$, this technique can detect small shifts as $\delta=1 \times 10^{-7} \mathrm{~m}$ (assuming that $M=2000 \times$ ), knowing that the theoretical limit is in order of $1 \times 10^{-8} \mathrm{~m}$. The expansivity of the filament material can be approximated by the equation,

$$
\frac{\Delta l}{l} \approx \frac{\Delta D^{\prime}}{D_{o}^{\prime}}
$$

The setup must operate at dark room noting that at incandescent temperature the illumination of the sample may present a problem, therefore a proper sample housing is needed for masking scattered lighting. Figure 4 shows the test setup during operation.

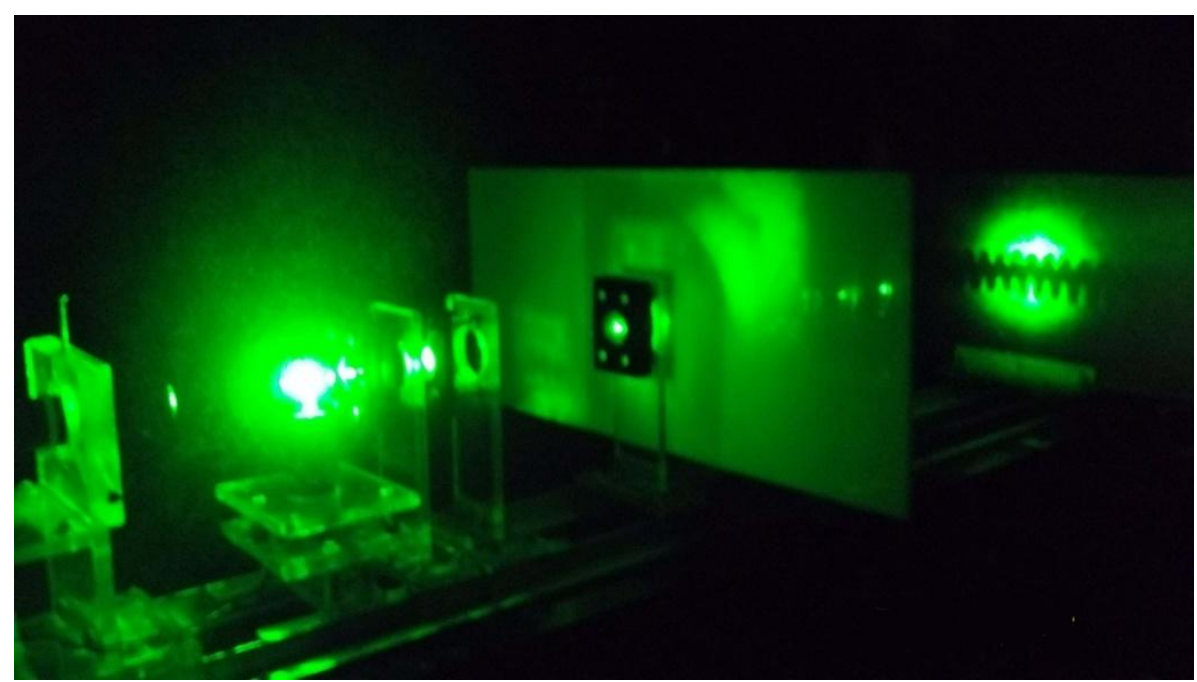

Figure 4. Dark room operation of filament dilatometer

The test procedure is summarized in figure 5 , where $d$ is the diameter of the filament wire, $\mathrm{I}$, $\mathrm{V}$ are the current and voltage across the filament, $\mathrm{W}$ is the nominal wattage, $\mathrm{I}_{\max }$ is the maximum current $\mathrm{I}_{\mathrm{op}}, \mathrm{V}_{\mathrm{op}}$ are the nominal operating current and voltage for the filament. 
Military Technical College

Kobry Elkobbah, Cairo, Egypt

April 3-5,2018 9th International Conference

on Mathematics and

Engineering Physics (ICMEP-9)

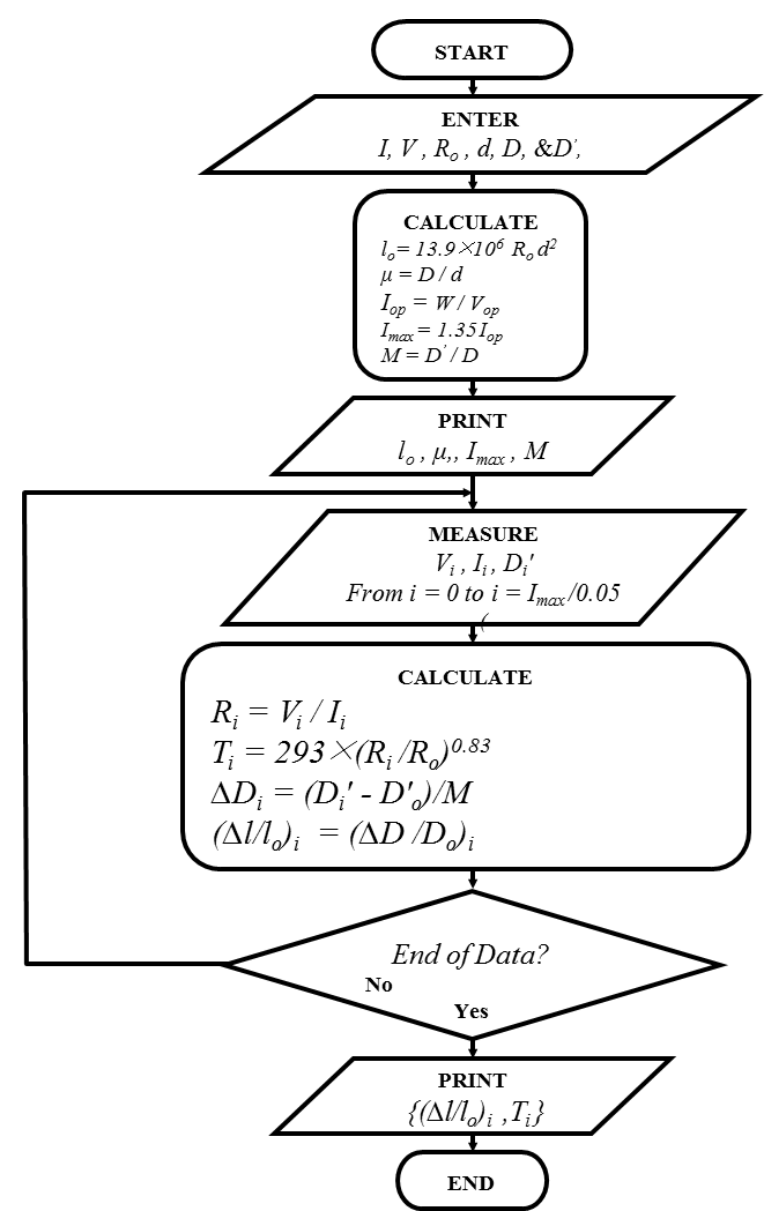

Figure 5. Flow chart of filament dilatometry

\section{Results and discussion}

We preformed sample shadowgraphy using 3 different laser wavelengths as seen in figure 6.a, 6.b, 6,c. it has been noticed that the most confortable one for the human eye was the red and the green.

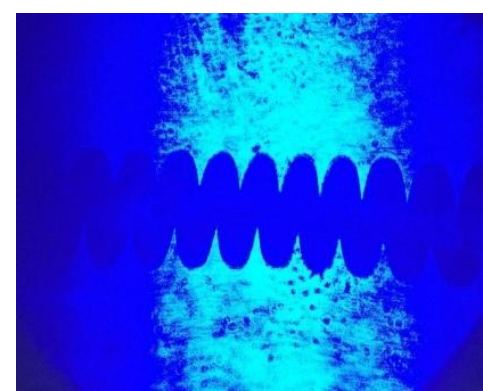

(a)

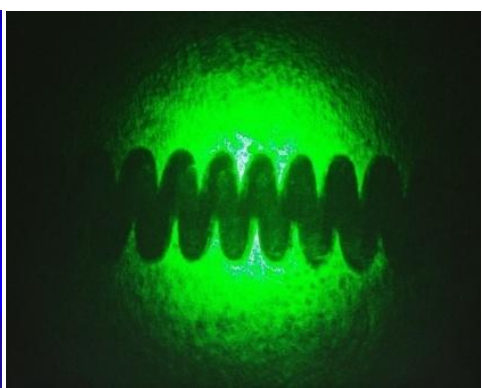

(b)

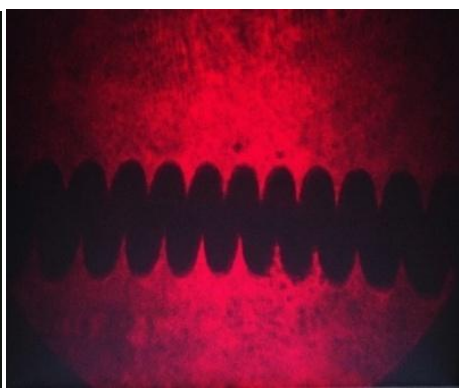

(c) 
Military Technical College

Kobry Elkobbah, Cairo, Egypt

April 3-5,2018 9th International Conference

on Mathematics and

Engineering Physics (ICMEP-9)

Figure 6. Filament shadowgraph image at (a) $436 \mathrm{~nm}$ (b) $536 \mathrm{~nm}$ and (c) $640 \mathrm{~nm}$

By applying digital zoom to each shadowgraphic picture (figure 7) then applying gray scale filter (figure 8) we noticed that the best contrast for digital photography of shadowgraph was given by blue laser ( Figure 8.a).

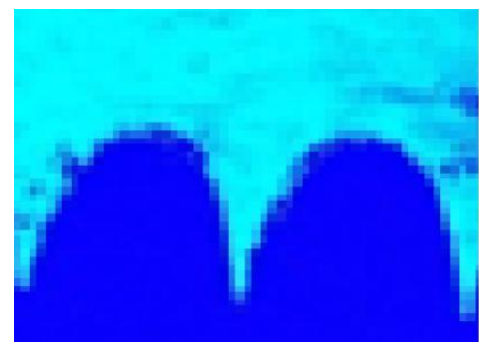

(a)

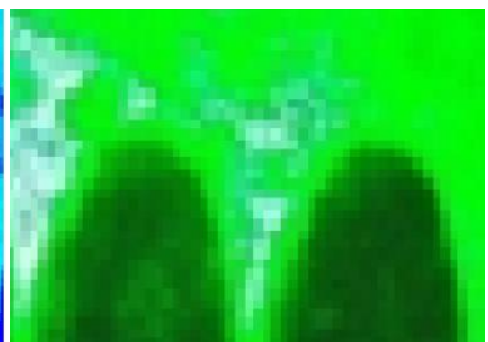

(b)

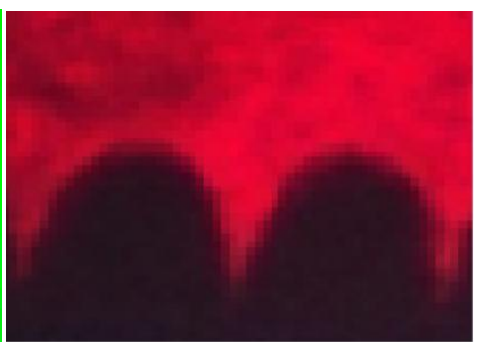

(c)

Figure 7. Digital zoom on filament edge shadowgraph images at (a) $436 \mathrm{~nm}$ (b) $536 \mathrm{~nm}$ and (c) $640 \mathrm{~nm}$

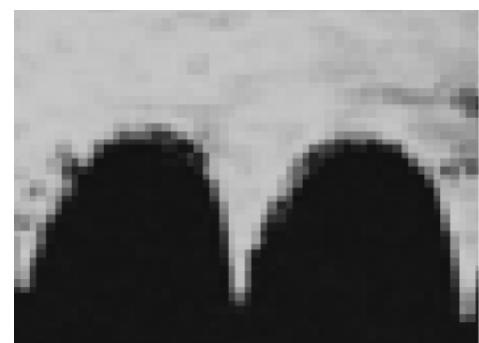

(a)

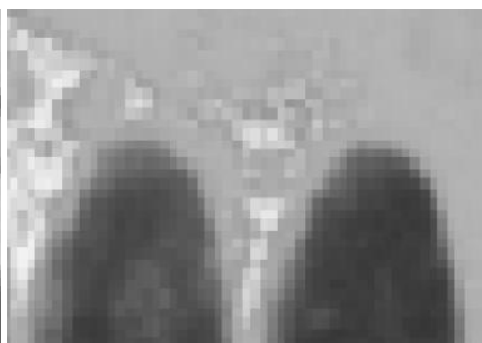

(b)

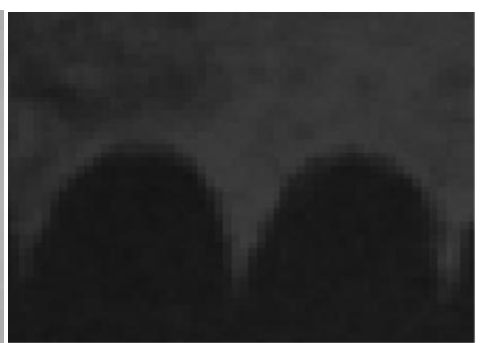

(c)

Figure 8. Gray scale digital zoom filament edge shadowgraph images at (a) $436 \mathrm{~nm}$ (b) 536 $\mathrm{nm}$ and (c) $640 \mathrm{~nm}$

We measured the expasivity of tungsten filament as a function of its temperature up to melting point and burnout. We obtained a very good agreement with the data of reference [10] as shown in figure 9. 
Military Technical College

Kobry Elkobbah, Cairo, Egypt

April 3-5,2018 9th International Conference

on Mathematics and

Engineering Physics (ICMEP-9)

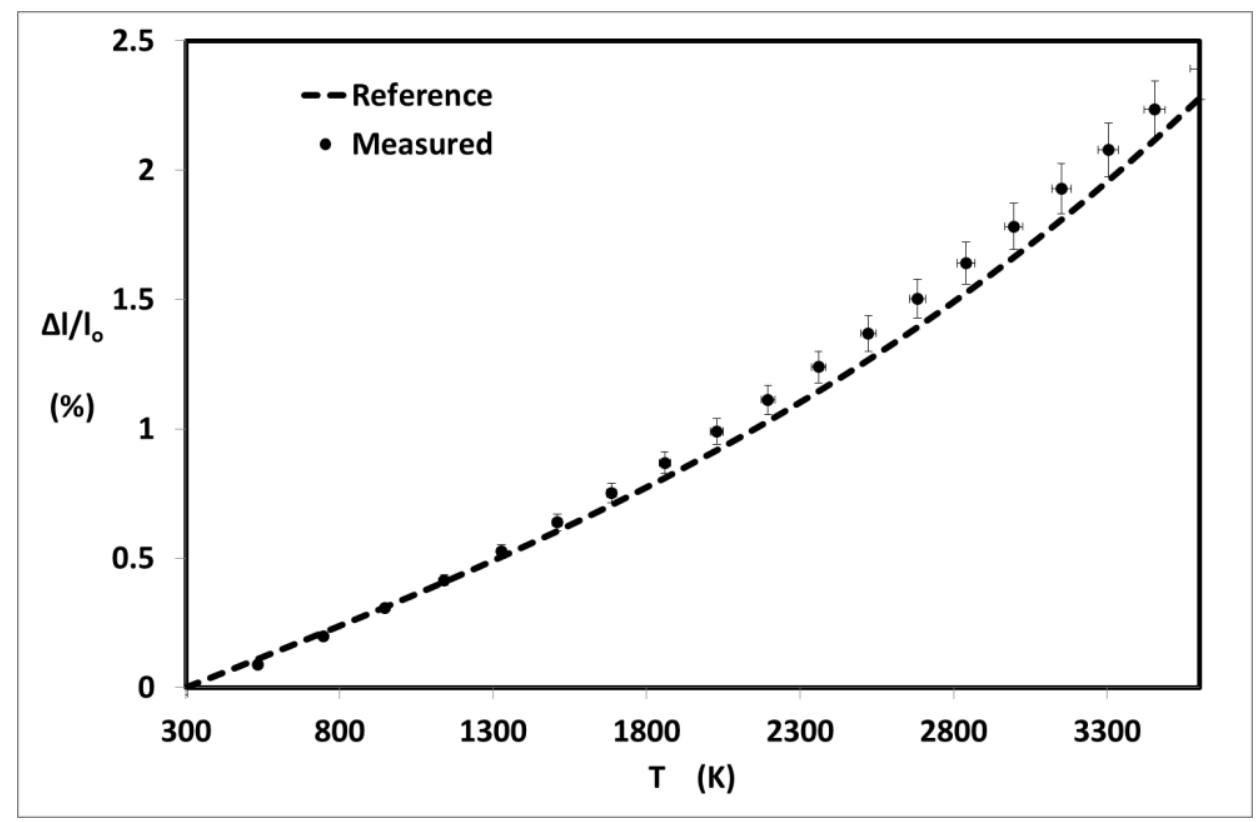

Figure 9. Measured expansivity of tungsten compared to the values of ref.[10]

Best results were obtained when using filaments of maximum ratio between coil diameter and its core wire cross section.

\section{Conclusion}

A one watt blue $(450 \mathrm{~nm})$ commercial multimode semiconductor laser has proven to be a suitable backlighting source, to generate shadowgraphs of incandescent objects, while green or red laser $(532 \mathrm{~nm}$ or $650 \mathrm{~nm})$ was not of the same effectiveness. The expansion of coil diameter is the key parameter that represents the linear expansion of the sample,. The measured tungsten expansivity values came in good agreement with the previously published data. This low cost method successfully attained a resolution of $5 \times 10^{-8} \mathrm{~m}$.

\section{Acknowledgment}

The authors are very grateful to the members of Physics Department, Faculty Science, Cairo University, for their support with measurement instruments, encouragement and helpful suggestions.

\section{References}

1. Tietz, T. E. and Wilson, J. W., Behavior and Properties Of Refractory Metals, Stanford University Press, Stanford, CA, p1-28. ISBN 978-0-8047-0162-4 (1965). 
April 3-5,2018

2. Wirtz, O. M., Thermal Shock Behavior of Different Tungsten Grades under Varying Conditions, Forschungszentrum, Jülich, ISBN 978-3-89336-842-6 (2013).

3. Taylor, R. E. et al, Thermal Expansion of Solids, Materials, Park, OH: ASM Int., ISBN 0-87170-623-7 (1998).

4. Bernard Yates, Thermal Expansion, Plenum Press, New York (1972).

5. PHYWE Co., Dilatometer with clock gauge, Instruction brochure (2014)

6. E. G. Wolff, Measurement Techniques for Low Expansion Materials, 9th National SAMPE Technical Conference, AtlantaGa, 9, 57-72, 1977.

7. Agrawal, D.C. and Menon, V. J., Illuminating physics with gas-filled lamps: Exponent-rule, Latin American J. of Phys. Educ., 3, 33-36 (2009).

8. H.H. Hassan, S.A. Khairy and H.S. Ayoub, A Simple Laboratory Experiment for Measuring the Expansivity of Tungsten at Elevated Temperatures, Nature and Science; 13(11), 146-151, 2015.

9. Subramaniamy, S., White, D. R., Scholl, D. J. and Weber, W. H., In situ optical measurement of liquid drop surface tension in gas metal arc welding, J. Phys. D: Appl. Phys. 31, 1963-1967 (1998).

10. White, G. K., and Minges, M. L., Thermophysical properties of some key solids: An update, International Journal of Thermophysics ,18, 5, 1269-1327 (1997). 